\title{
UMA ESTIMATIVA DO CUSTO DE SUBORDINAÇÃO DA DÍVIDA FINANCEIRA ESTABELECIDA PELA ATUAL LEI DE FALÊNCIA
}

\author{
JOSÉ ROBERTO SECURATO \\ Professor Associado do Departamento de Administração da FEA/USP - SP \\ Professor Titular da PUC São Paulo - SP \\ E-mail: securato@usp.br
}

\section{LILIAM SANCHEZ CARRETE}

Doutoranda em Administração de Empresas pela FEA-USP - SP

E-mail: Iscarrete@labfin.com.br

\section{JOSÉ ROBERTO FERREIRA SAVOIA}

Professor Doutor do Departamento de Administração da FEA/USP - SP

E-mail: jrsavoia@usp.br

\section{RESUMO}

Este trabalho tem como objetivo verificar o impacto no custo de endividamento das empresas devido à ordem de prioridade de pagamento das dívidas corporativas em caso de falência. A nova Lei de Falência em tramitação no Congresso Nacional, Projeto de Lei 4.376, define a ordem de classificação dos créditos na falência pelo artigo 83. A atual Lei de Falência estabelece que as dívidas trabalhistas, previdenciárias e tributárias possuem prioridade de pagamento às demais dívidas. Entende-se, portanto, que existe uma subordinação das dívidas contratadas junto aos bancos e investidores com relação aos passivos prioritários. Este estudo estima o custo de subordinação do passivo financeiro - empréstimos e financiamentos - aos passivos com preferência de pagamento. Primeiro, obteve-se evidência a favor do modelo de precificação, através da comparação do valor do passivo obtido pela aplicação do modelo com o valor de mercado, e finalmente, calculou-se uma média de 0,30\%a.a. de custo de subordinação dos passivos financeiros.

Palavras-chave: Modelo Binomial, Passivo, Dívidas Subordinadas, Títulos Híbridos

\section{ABSTRACT}

This paper studies the debt cost effect caused by the payment order when liquidating its liabilities in case of corporate bankruptcy established by the current Bankruptcy Legislation. The new Bankruptcy Legislation under discussion at the Brazilian Congress, Law project 4.376, defines the liability ranking order in case of Bankruptcy in article 86. The current Brazilian bankruptcy regulation defines that employee, social security and fiscal liabilities must be settled before other liabilities such as asset backed debt securities, suppliers and loans. Therefore, there is a subordination of financial liabilities - loans and financing contracted with banks and investors compared to those liabilities with liquidation priority. This research estimates the cost of subordination of financial liabilities. First, we applied the binomial model to estimate the present value of corporate liabilities and its components such as call option, put option and subordination and, finally, we estimated an average of $0.30 \%$ p.a. of subordination cost of financial liabilities in relation to liabilities with settlement priority.

Keywords: Binomial Model, Financial Debt, Subordinated Debt, Hybrid Securities 


\section{INTRODUÇÃO}

A nova Lei de Falência em tramitação no Congresso Nacional, Projeto de Lei 4.376, altera o processo de falência, que consiste no procedimento judicial para a coleta, disposição e liquidação dos ativos de uma empresa. O artigo 86 do Projeto de Lei define como os créditos são classificados em caso de falência, questão objeto de estudo deste trabalho. A atual Lei de Falência, Decreto-lei 7.661/45 e suas alterações: Leis 3.726/60, 4.983/66, 6.014/73, 5.458/77, 7.274/84 e 8.131/ 90 , estabelecem que os créditos dos empregados, caracterizados por salários e indenizações trabalhistas, assim como os créditos tributários e previdenciários, possuem preferência sobre os credores de dívidas da massa que compreendem os créditos com direitos reais de garantia e créditos quirografários (art. 102 do Decreto-Lei 7.661). Por último, os acionistas, proprietários da empresa recebem o saldo dos ativos não liquidados. Essa ordem de prioridade caracteriza uma subordinação dos passivos não classificados como dívidas trabalhistas, fiscais e previdenciárias.

Uma dívida subordinada, cujo pagamento se dará somente se as dívidas com preferência de pagamento forem liquidadas, apresenta um risco maior do que as dívidas com mesma prioridade de pagamento das demais e, por isso, deve ser negociada com um prêmio para compensar o investidor pelo maior risco. Então, as dívidas contratadas com o setor financeiro, as chamadas dívidas financeiras, devem incorporar um prêmio devido à sua subordinação às dívidas trabalhistas, tributárias e previdenciárias. Este custo impacta no custo de capital das empresas o que determina a taxa de corte utilizada nas decisões de investimento pelas empresas.

Este trabalho aplica o modelo binomial de precificação ${ }^{1}$ de títulos de dívida corporativos de Barth et al. (2000) para avaliar o modelo de precificação incluindo o aspecto de subordinação das dívidas financeiras aos passivos prioritários e obter uma estimativa do prêmio decorrente dessa subordinação.

\section{OBJETIVO}

Este trabalho tem como objetivo estimar o prêmio cobrado pelos credores em decorrência da subordi- nação dos passivos financeiros aos passivos prioritários, imposta pela atual Lei de Falências. Para isso, o estudo realiza a aplicação da metodologia de precificação de títulos de dívida proposta por Barth et al. (2000), o qual leva em consideração, além da subordinação, outros componentes embutidos nos títulos de dívida.

\section{O MODELO BINOMIAL DE PRECIFICAÇÃO DE DÍVIDA CORPORATIVA}

As dívidas apresentam características diferentes entre si e cada uma delas influencia o valor de todas as dívidas de uma empresa. Além da subordinação aos passivos prioritários, serão considerados os demais componentes embutidos nas emissões de debêntures e eurobônus: (i) opção de compra, para a empresa, antes do vencimento do título - call; (ii) opção de venda, para o credor, antes do vencimento do título - put; (iii) direito de converter a dívida em ações da empresa - conversibilidade e (iv) subordinação do título aos demais passivos exigíveis da empresa.

O último componente, subordinação, refere-se aos títulos emitidos com prioridade de pagamento somente aos acionistas da empresa. Os preços desses títulos não são influenciados pela Lei das Falências, uma vez que já são subordinados a todos os outros passivos da empresa.

Quando uma empresa faz uma nova captação de recursos, altera o valor das demais dívidas, portanto, os valores das dívidas contratadas de uma empresa devem ser determinados em conjunto. Barth et al. (2000) sugerem que a precificação das dívidas seja realizada em conjunto, considerando que os credores estão posicionados como comprados nos ativos da empresa e vendidos em uma call e os acionistas da empresa estão posicionados comprados na call. Se o valor dos ativos da empresa estiver abaixo do valor da dívida, a empresa não conseguirá pagar integralmente seus credores, portanto, estes pedirão sua falência e receberão seu ativo. Nesse caso, os acionistas não recebem nada. Por outro lado, se o valor dos ativos estiver acima do valor da dívida, a empresa pagará, integralmente, seus credores e os acionistas receberão o valor total da 
empresa, subtraído dos passivos exigíveis. Se o valor total dos ativos não for suficiente para pagar o total das obrigações, os credores seniores receberão primeiro e os credores subordinados receberão o saldo dos ativos. Os acionistas só recebem se o ativo total da empresa for maior que o total devido aos credores.

\subsection{A Árvore Binomial}

Barth et al. (2000) aplicam o modelo binomial para estimar o valor dos ativos da empresa, nos períodos seguintes, até o ano de vencimento do título de dívida mais longo da empresa. Considera-se que os de- mais títulos que vencem antes do título mais longo são renovados nas condições originais. Parte-se da premissa de que todos os passivos vencem no último ano do período binomial.

Para a construção da árvore binomial (figura 1), parte-se do valor inicial dos ativos da empresa, na data em que se quer precificar, como sendo o valor contábil do passivo exigível somado ao valor de mercado do patrimônio líquido da empresa. Os valores totais dos ativos da empresa dos demais períodos são calculados aplicando-se os multiplicadores dos estados de alta e de baixa u e d, utilizando a volatilidade histórica das ações para sua determinação.

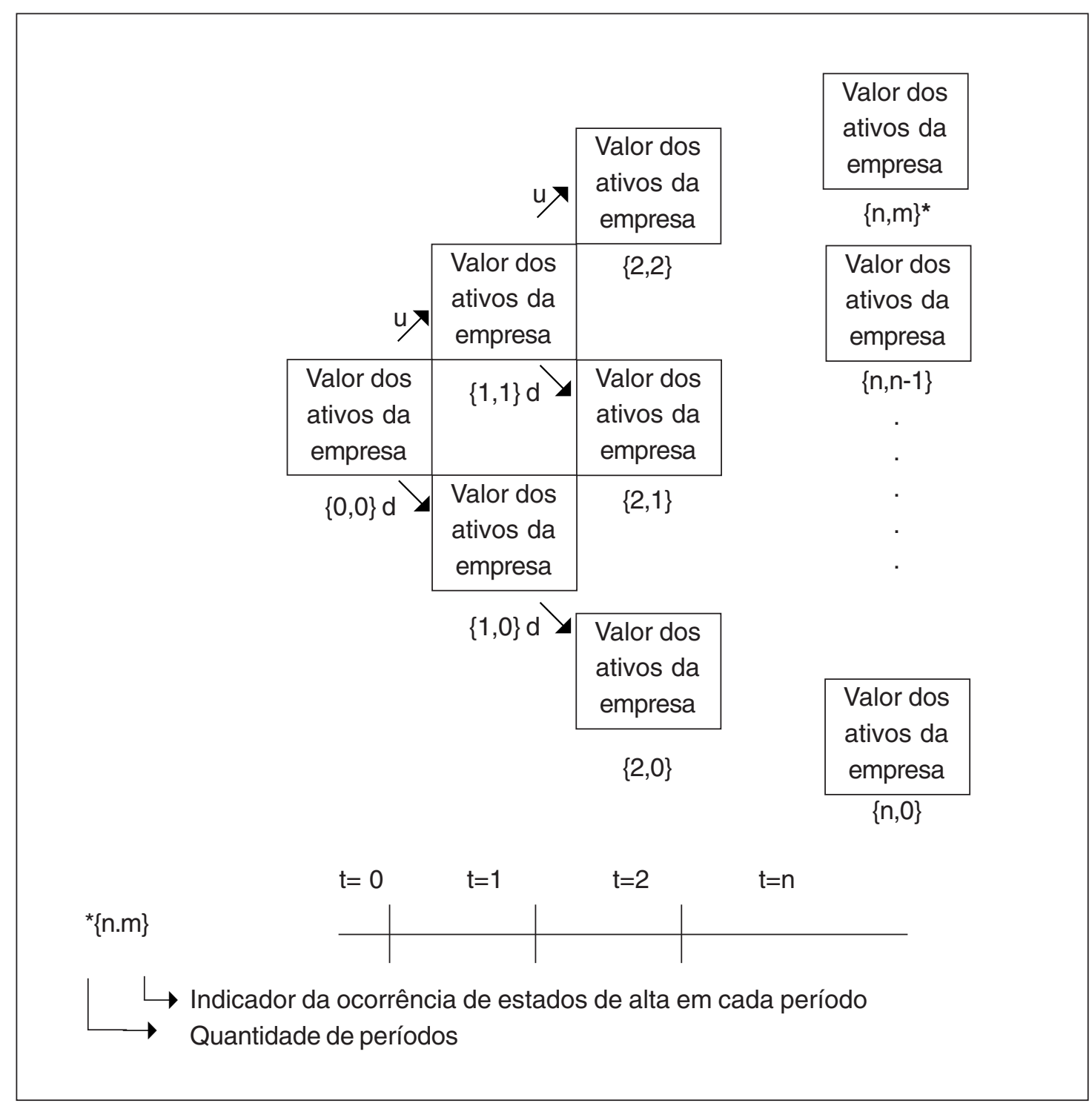

Figura 1: Representação da Árvore Binomial do valor dos ativos da empresa 
Sabe-se que u e d são obtidos a partir de Cox, Ross e Rubinstein (1979) e dados por:

$$
\begin{gathered}
\boldsymbol{u}=\exp \left(\frac{\mu}{\boldsymbol{T}}+\frac{\sigma}{\sqrt{\boldsymbol{T}}} \times \sqrt{\frac{1-\boldsymbol{P}}{\boldsymbol{P}}}\right) \quad \boldsymbol{d}=\exp \left(\frac{\mu}{\boldsymbol{T}}-\frac{\sigma}{\sqrt{\boldsymbol{T}}} \times \sqrt{\frac{1-\boldsymbol{P}}{\boldsymbol{P}}}\right) \\
\mathrm{e} \\
\boldsymbol{P}=\frac{\boldsymbol{R}_{\boldsymbol{t}}-\boldsymbol{d}}{\boldsymbol{u}-\boldsymbol{d}}
\end{gathered}
$$

Essas expressões podem ser aproximadas, conforme Rendleman e Bartter (1979), por:

$$
\boldsymbol{u}=\exp \left(\frac{\boldsymbol{R} t}{\boldsymbol{n}}-\frac{\frac{1}{2} \sigma^{2} t}{n}+\frac{\sigma \sqrt{\boldsymbol{t}}}{\sqrt{n}}\right) \quad \boldsymbol{d}=\exp \left(\frac{\boldsymbol{R} t}{\boldsymbol{n}}-\frac{\frac{1}{2} \sigma^{2} t}{n}-\frac{\sigma \sqrt{\boldsymbol{t}}}{\boldsymbol{n}}\right)
$$

em que:

$\mu$ : $\quad$ taxa média de variação do ativo

$\sigma: \quad$ volatilidade do ativo

$\mathrm{p}$ : probabilidade risco neutro

$\mathrm{R}_{\mathrm{t}}$ : taxa livre de risco do período $\mathrm{t}$

$\mathrm{t}$ : $\quad$ medida de tempo de cada período

$\mathrm{n}$ : número de sub-período por período

\subsection{Precificação do Título}

Para se precificar os títulos da dívida da empresa deve-se, inicialmente, selecionar um título de dívida indicado por título $\mathrm{A}$, considerando os demais passivos exigíveis como um segundo título de dívida $\bar{A}$. Em seguida, para cada um dos valores do último período da árvore binomial o valor do ativo da empresa será dividido em três partes:
- valor do título que se quer precificar;

- valor dos demais passivos exigíveis;

- valor do capital próprio: resultado da subtração do valor do ativo da empresa pelos passivos exigíveis.

Então, a partir do último nó da árvore binomial calcula-se o valor presente do título dado por:

$$
\boldsymbol{V} \boldsymbol{P}_{t, j}=\frac{\boldsymbol{V}_{t+1, j+1} \boldsymbol{P}+\boldsymbol{V}_{t+1, j}(1-\boldsymbol{P})}{\boldsymbol{r}}
$$

em que:

$\mathrm{VP}_{\mathrm{t}, \mathrm{j}} \quad=$ valor presente do título no período $\mathrm{t}$

$\mathrm{V}_{\mathrm{t}+1, \mathrm{~J}+1}=$ valor do título no período $\mathrm{t}+1$ e $\mathrm{j}+1$ estados de alta

$\mathrm{V}_{\mathrm{t}+1, \mathrm{~J}}=$ valor do título no período $\mathrm{t}+1 \mathrm{e} \mathrm{j}$ estados de alta

$r=1+$ taxa de juros livre de risco

$\mathrm{P}=$ fator de probabilidade risco neutro 
Esses cálculos são repetidos para cada período da árvore como aparece na figura seguinte:

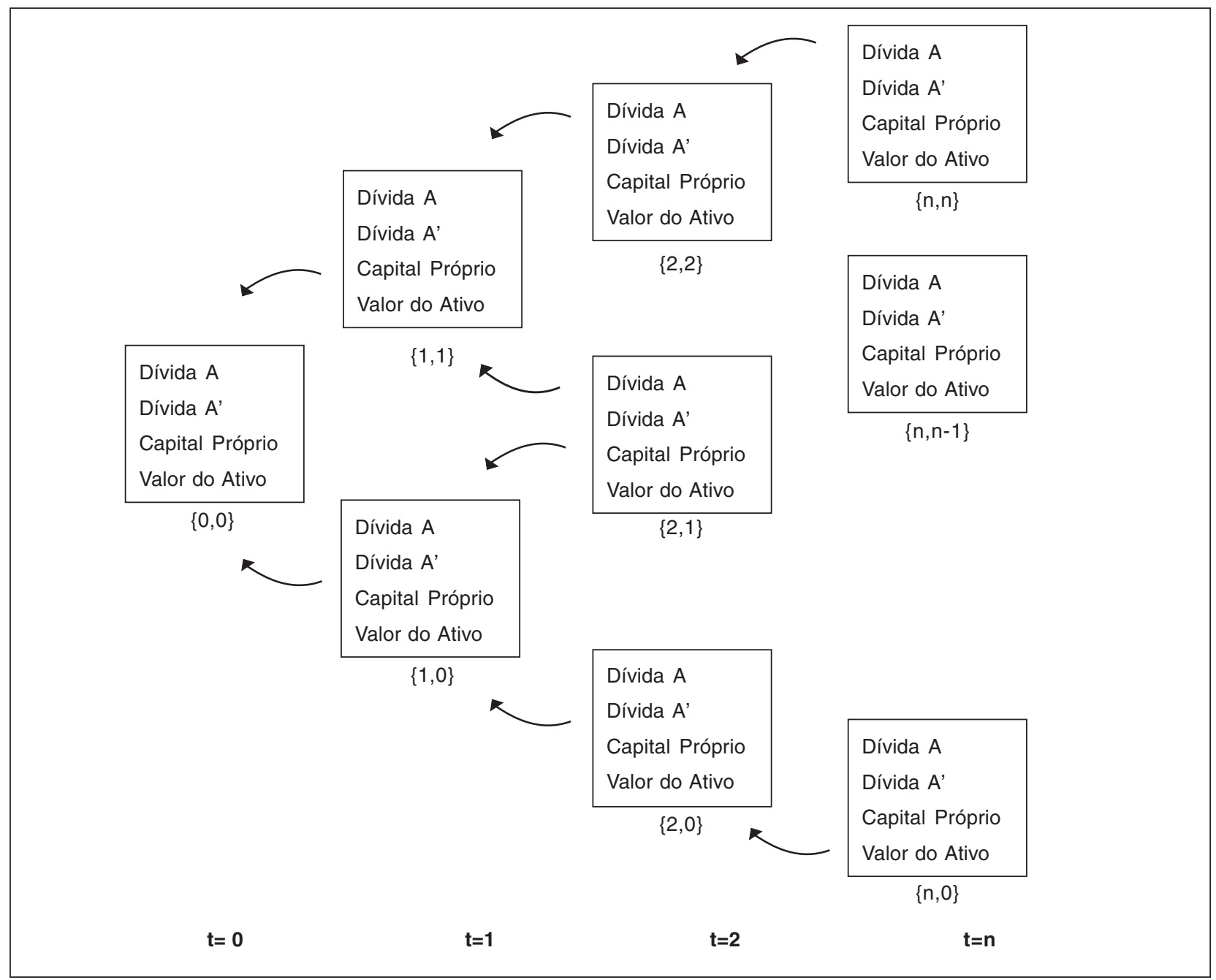

Figura 2: Representação precificação dos títulos

Em seguida, seleciona-se um segundo título para ser precificado, título $B$; considerando os demais passivos exigíveis como um segundo título de dívida $\bar{B}$ (incluindo o título $A$, já precificado). $\mathrm{E}$ repete-se o processo precificando todos os outros passivos que possam existir.

\subsection{Volatilidade dos Ativos}

Para cada um dos títulos de dívida obtém-se seu preço na data de hoje que pode ser comparado com o respectivo preço do mercado. Substituindo o preço do título a mercado e calculando a volatilidade, obtém-se o que costuma ser chamado de volatilidade implícita. No caso, ter-se-ia uma volatilidade implícita para cada título de dívida, o que não faz sentido. Considere-se, então, a soma dos erros quadráticos entre os preços a mercado e do modelo, dos títulos de dívida, dada por:

$$
\boldsymbol{T}=\sum_{j=1}^{n}\left(\frac{\text { pmercado }_{j}}{\text { p modelo }_{j}}-1\right)^{2} \quad \text { em que: }
$$

Pmercado=preço de mercado do título

Pmodelo=preço do título estimado pelo modelo

Conforme metodologia de Barth et al. (2000) procura-se o valor da volatilidade que minimiza o valor de T e considera-se essa volatilidade, induzida pelo modelo, a melhor estimativa para a volatilidade dos ativos. Volta-se a precificar cada um dos títulos de dívida utilizando a volatilidade 
implícita e obtêm-se os prêmios dos elementos contingenciais dos contratos.

\subsection{Critério de Decisão do Valor do Passivo}

Em cada um dos períodos estimados pela árvore binomial, o valor do título depende de contingências existentes nos títulos de dívida. O critério de decisão aplicado neste trabalho abrange os componentes: (i) opção de compra, (ii) opção de venda; (iii) opção de conversão, (iv) subordinação do título de dívida aos demais passivos exigíveis da empresa e (v) subordinação aos passivos prioritários (passivos trabalhistas, tributários e previdenciários). Veja-se o tratamento para cada caso.

\section{a) Opção de Compra}

Se o título oferecer uma opção de compra para o emissor, então este exercerá a opção caso o valor de recompra seja menor que o valor de manter o título no mercado. O valor de recompra é definido no lançamento do título e o valor de manutenção do título é obtido pelo valor presente calculado pela equação $\mathrm{VP}_{\mathrm{t}, \mathrm{j}}$, observando que ao final do período, no vencimento, a opção torna-se nula. Caso o título apresente, ainda, a opção de conversão, então, aplica-se o critério de conversão descrito a seguir. E por último, verifica-se o valor total do ativo da empresa; caso não seja suficiente para o pagamento integral do passivo exigível, então, aplicam-se os critérios de Senioridade e Subordinação que também são examinados a seguir.

\section{b) Opção de Venda}

Se o título incluir uma opção de resgate antecipado ao investidor, então ele poderá resgatar seus recursos quando o valor de resgate do título for maior que o valor de manutenção do investimento. $O$ valor de manutenção do título é calculado pela equação $V P_{t, j}$. Verifica-se se o valor do ativo total é suficiente para liquidação dos passivos exigíveis e caso seja menor que o passivo, aplicam-se os critérios de Subordinação e Senioridade.

\section{c) Opção de Conversibilidade}

Se o título possuir opção de conversão para o investidor, então compara-se o valor nominal somado aos juros com o valor convertido em ações, registra-se o maior valor, uma vez que o investidor busca maximizar sua riqueza. Se o valor do ativo não for suficiente para pagamento integral do passivo, então, aplicam-se os critérios de Senioridade e Subordinação.

\section{d) Cláusulas de Senioridade e Subordinação}

- se o valor total do ativo da empresa for maior que o valor nominal somado aos juros devidos dos títulos de dívida, então registra-se o valor nominal do título somado aos juros devido.

- Se o valor total do ativo da empresa for menor que o valor nominal dos títulos de dívida, então:

i. Se o título de dívida for subordinado, então, seu valor será o valor total do ativo da empresa subtraído do valor nominal + juros dos demais passivos exigíveis;

ii. Se o título de dívida tiver mesma prioridade de pagamento aos demais passivos exigíveis, então, registra-se a proporção da dívida que está sendo precificada sobre a dívida total multiplicada pelo valor do ativo da empresa;

iii. Se o título de dívida for sênior, com prioridade de pagamento aos demais passivos, então, registra-se o valor nominal do título somado aos juros se o valor do ativo da empresa for suficiente. Caso contrário registrase somente o valor do ativo da empresa.

iv. Se o título de dívida for subordinado a passivos prioritários, então, seu valor nominal será a multiplicação do ativo total pela proporção da dívida que está sendo precificada sobre a dívida total reduzida do passivo preferencial, o qual possui prioridade sobre o ativo total. 


\subsection{Os Passivos Exigíveis que não são Títulos de Dívida}

Os passivos exigíveis, que não são títulos de dívida, correspondem, entre outros, aos passivos tributários, fornecedores, passivos trabalhistas e provisão para contingências e serão considerados títulos de dívida com pagamento de juros periódicos, cujo valor nominal estimado é o valor contábil. A taxa de juros pode ser estimada por meio do custo de capital de terceiros com base em dados de mercado. Uma das formas para realizar tal estimativa pode ser vista em Minardi e Sanvicente (2003), outra forma, conforme o perfil dos passivos e do tamanho da empresa, consiste em supor que os recursos podem ser captados à própria taxa livre de risco.

\section{ESTIMATIVA DO CUSTO DE SUBORDINAÇÃO DOS PASSIVOS FINANCEIROS AOS PASSIVOS PRIORITÁRIOS}

Neste trabalho, classifica-se o passivo exigível das empresas em: (i) passivos prioritários: passivos trabalhistas, tributários e previdenciários; (ii) passivos financeiros: empréstimos e financiamentos e debêntures e (iii) passivos não onerosos: fornecedores, provisões para contingência e demais contas que não se enquadram nas categorias (i) e (ii). Vale ressaltar que apesar da denomiação desta última categoria (iii), estes passivos possuem custos, entretanto, diferentemente dos empréstimos, financiamentos e títulos de dívida, cujos custos são explícitos, os passivos não onerosos apresentam custos implícitos. A estimativa de cada categoria é realizada com base nas contas divulgadas pelas demonstrações financeiras.

O custo de subordinação dos passivos financeiros aos passivos prioritários é estimado através do cálculo do prêmio obtido pela divisão da taxa de retorno dos passivos financeiros, calculada com característica de subordinação aos passivos prioritários, pela taxa de retorno desses passivos, calculada considerando-os de mesma prioridade a todos os demais passivos exigíveis.

$$
\text { premio }=\frac{1+\text { txdivsubord }}{1+\text { txdiv }}-1 \quad \text {, em que: }
$$

Txdivsubord é a taxa de retorno da dívida financeira quando esta for subordinada às dívidas prioritárias. É calculada utilizando os preços obtidos pela aplicação do modelo de precificação, considerando cada uma das dívidas financeiras como subordinada aos passivos prioritários. Quando a debênture ou eurobônus for subordinado, então, este título mantém sua característica original de subordinação a todos os demais passivos exigíveis. O fluxo de caixa utilizado para calcular a taxa de retorno é resultante da soma do valor presente de todos os títulos que compõem o passivo financeiro, representando o investimento inicial dos investidores. Os fluxos intermediários são determinados pela soma dos juros anuais pagos pelos títulos de dívida e o fluxo final refere-se ao valor nominal somado aos juros pagos pelos títulos, representando a liquidação dos investimentos.

Txdivé calculada da mesma forma que a txdivsubor, entretanto considerando que cada título de dívida tenha a mesma prioridade de pagamento de todos os outros passivos. Preserva-se a característica de subordinação dos títulos emitidos com tal componente.

\section{APLICAÇÃO DO MODELO}

Realizou-se a avaliação do valor presente das dívidas das empresas, utilizando as informações divulgadas pelas empresas no terceiro trimestre de 2003. A amostra é composta por sociedades anônimas de capital aberto com disponibilidade de informações de seus títulos de dívida: debêntures e bônus internacionais, limitando-se a amostra a 14 empresas. A classificação do passivo exigível das empresas foi realizada com base nas contas do Balanço Patrimonial apresentado no sistema de informações da CVM, Divext.

A base de dados que compõem a amostra do trabalho é apresentada no quadro 1, que inclui informações sobre endividamento das empresas, assim como os valores dos passivos prioritários, passivos não financeiros e passivos financeiros. A última coluna refere-se ao prazo de vencimento de todos os títulos de dívida da empresa, o qual é estimado como sendo o prazo do título de dívida mais longo da empresa. 


\begin{tabular}{|c|c|c|c|c|c|c|c|}
\hline \multicolumn{8}{|c|}{$\begin{array}{c}\text { Valor } \\
\text { Contábil }\end{array}$} \\
\hline Base de Dados & $\begin{array}{l}\text { Passivos } \\
\text { Prioritários }\end{array}$ & $\begin{array}{c}\text { Passivos não } \\
\text { Financeiros }\end{array}$ & $\begin{array}{l}\text { Passivos } \\
\text { Financeiros }\end{array}$ & $\begin{array}{c}\text { Passivo } \\
\text { Exigível } \\
\text { Total }\end{array}$ & $\begin{array}{c}\text { PL- } \\
\text { Mercado }\end{array}$ & Endividamento & $\begin{array}{l}\text { Prazo } \\
\text { (anos) }\end{array}$ \\
\hline Pão de Açucar & $1,223,698$ & 979,303 & 522,381 & $2,725,382$ & $6,055,458$ & $31.04 \%$ & 4 \\
\hline Braskem S.A. & 589,472 & $4,978,300$ & $4,889,770$ & $11,582,389$ & $2,414,000$ & $82.75 \%$ & 3 \\
\hline Brasil Telecom S.A. & $1,598,061$ & $1,742,196$ & $4,798,114$ & $8,138,371$ & $6,999,999$ & $53.76 \%$ & 2 \\
\hline Cemig & $2,729,231$ & $1,934,360$ & $3,359,154$ & $8,022,745$ & $4,282,217$ & $65.20 \%$ & 8 \\
\hline Acesita S.A. & 368,536 & 470,628 & $1,698,446$ & $2,537,610$ & 965,826 & $72.43 \%$ & 3 \\
\hline Petróleo Brasileiro S.A. & $16,134,649$ & $34,853,921$ & $10,250,120$ & $61,238,690$ & $69,802,703$ & $46.73 \%$ & 9 \\
\hline$\overline{\mathrm{CSN}}$ & 654,086 & $5,172,380$ & $9,732,816$ & $15,559,282$ & $7,402,460$ & $67.76 \%$ & 10 \\
\hline \multicolumn{8}{|l|}{ Usinas Siderúrgicas } \\
\hline de Minas Gerais S.A. & 150,091 & $2,197,356$ & $2,631,662$ & $4,979,109$ & $3,635,777$ & $57.80 \%$ & 2 \\
\hline Duratex S.A. & 121,587 & 127,891 & 364,508 & 613,986 & 703,039 & $46.62 \%$ & 4 \\
\hline CESP & $1,813,784$ & 702,293 & $10,202,029$ & $12,718,106$ & 821,837 & $93.93 \%$ & 8 \\
\hline \multicolumn{8}{|l|}{ Telesp Celular } \\
\hline Participações S.A. & 644 & 207,232 & $3,695,495$ & $3,903,371$ & $5,795,288$ & $40.25 \%$ & 5 \\
\hline CPFL Energia S.A. & 108 & 800,128 & $1,018,974$ & $1,819,210$ & 413,837 & $81.47 \%$ & 5 \\
\hline SABESP & 662,504 & 906,416 & $7,353,611$ & $8,922,531$ & $3,586,433$ & $71.33 \%$ & 5 \\
\hline Paranapanema S.A. & 7,877 & 6,901 & 844,780 & 859,558 & 473,584 & $64.48 \%$ & 4 \\
\hline
\end{tabular}

Quadro 1: Empresas da Amostra

Os passivos financeiros incluem os títulos de dívida: debêntures e eurobônus emitidos pela empresa. A aplicação do modelo de precificação depende de que cada uma das empresas possua, pelo menos um de seus títulos de dívida, negociados no mercado secundário na data de precificação. As 14 empresas possuem 56 títulos de dívida emitidos, dos quais 37 foram negociados no mercado secundário em pelo menos um dia dos meses de setembro e outubro de 2003.

As informações sobre os Eurobonds são coletadas pelo sistema de informações Bloomberg, o qual apresenta os componentes call, conversibilidade e subordinação. As informações sobre as debêntures emitidas no mercado doméstico foram coletadas pelo sistema de informações da ANDIMA - Sistema Nacional de Debêntures (SND) que fornece uma descrição de cada um dos títulos através do Caderno de Debêntures. Esse sistema classifica as debêntures em subordinadas e não subordinadas, conversíveis e não conversíveis, permutáveis e não permutáveis. São três os componentes que fazem parte dos títulos da amostra: call, subordinação e conversibilidade. A call é caracterizada pela presença da cláusula de Resgate Antecipado (facultativo) válida por toda vida do título:

A emissora poderá resgatar antecipamente as debêntures, total ou parcialmente, a qualquer tempo a partir do mês contado da data de emissão,... As debêntures resgatadas antecipadamente serão obrigatoriamente canceladas. A emissora se compromete a não realizar nova emissão no mercado de capitais local antes de 90 dias contados a partir da data do exercício do resgate antecipado facultativo.

O valor de resgate no exercício da opção varia desde o valor nominal do título mais juros acruados até o pagamento de um prêmio, que varia de $0,5 \%$ até $1 \%$ do valor nominal mais juros acruados.

Dos 56 títulos de dívida avaliados, 17 apresentam call, e 7 apresentam subordinação às demais dívidas da empresa. Somente uma das empresas da amostra apresentou 3 títulos de dívida com cláusula de conversão em ações: Paranapanema S.A. A remuneração das debêntures consiste na participação dos lucros da emissora, com remuneração mínima de INPC + 6\%a.a., a qual foi utilizada para avaliação do preço dos títulos. A opção de conversibilidade é válida para toda a vida da debênture, sendo a taxa de conversão - quantidade de ações resultante da conversão de cada debênture - determinada mediante uma relação entre o valor unitário corrigido da debênture e a cotação da ação preferencial, diferentemente 
de uma taxa de conversão tradicional que é pré-definida na escritura de emissão do título.

Desenvolveu-se um programa em "Visual Basic for Aplications"- VBA para aplicação do modelo de precificação dos títulos de dívida, que consiste no cálculo do valor presente de cada um dos títulos de dívida que compõem o passivo exigível de cada uma das 14 empresas da amostra. Partindo do passivo exigível divulgado no ITR de 30 de setembro de 2003, estimou-se o valor contábil dos passivos prioritários, dos passivos não financeiros e dos passivos financeiros. As debêntures e eurobônus são títulos de dívida com custo explícito e os demais passivos são tratados como títulos de dívida, cujo custo estimado é a taxa livre de risco.

Cada empresa, então, passa a ter um passivo exigível composto por títulos de dívida que pagam juros anuais, sem possibilidade de capitalização. As taxas de juros dos títulos são consideradas taxas de juros reais (os juros nominais são descontados pela taxa de inflação), sendo que os juros pós-fixados são estimados com base nas expectativas dos indicadores apresentados a seguir:

$\begin{array}{lr}\text { US\$ } & 6 \% \text { a.a. } \\ \text { Inflação } & 6 \% \text { a.a. } \\ \text { TJLP } & 11 \% \text { a.a. } \\ \text { Tx Livre Risco } & 7.25 \% \text { a.a. } \\ \text { CDI } & 17 \% \text { a.a. } \\ \text { Tx Cambial (R\$/US\$) } & 3,00\end{array}$

Os títulos em moeda estrangeira-dólar foram convertidos para moeda Reais à taxa de R\$/US\$3,00. Foi suposto que as variações cambiais das moedas acompanhe a inflação em Reais.

Tendo coletado os dados das empresas e de seus títulos de dívida, o programa é executado para cada empresa individualmente, partindo do desenvolvimento da árvore binomial do valor total da empresa com intervalos anuais até a data de vencimento do título de dívida mais longo. $\mathrm{O}$ valor inicial dos ativos da empresa é a soma do valor contábil do passivo exigível e o valor de mercado da empresa, estimado pela quantidade de ações preferenciais e ações ordinárias multiplicadas pelas respectivas cotações em 30 de setembro de 2003. Utilizou-se a taxa livre de risco (taxa contínua) e a volatilidade histórica - calculada pela variação trimestral do preço da ação de maior liquidez da empresa - para calcular os parâmetros ue $d$, conforme descrito na seção "3.1. Árvore Binomial”.
Cada um dos títulos de dívida que formam o passivo exigível da empresa é precificado partindo, inicialmente, do último período da árvore binomial, quando o valor do título é determinado como uma participação no valor dos ativos da empresa. Essa participação é calculada somando o valor nominal e os juros do título em $\mathrm{R} \$$ desde que o valor dos ativos seja suficiente para pagar o total dos passivos exigíveis. Caso contrário, o título concorre com os demais passivos exigíveis pela ordem de preferência sobre os ativos da empresa. Se houver cláusula de conversibilidade, deve-se, então, realizar a comparação entre valor de conversão e valor de resgate do título, conforme especificado na seção "3.4. Critério de Decisão do Valor do Passivo".

A precificação das debêntures, com cláusula de conversibilidade, da Paranapanema S.A. foi realizada comparando-se, a cada período da árvore binomial, o valor da conversão com o valor presente do respectivo período. A estimativa do valor da conversão de cada debênture foi realizada calculando-se, primeiramente, o valor unitário da ação como sendo o valor dos ativos, subtraindo o valor presente do passivo exigível do período binomial dividido pela quantidade de ações da empresa. Segundo, calculou-se a taxa de conversão, quantidade de ações por debênture, resultante da divisão do valor nominal unitário das debêntures pelo valor unitário das ações. Terceiro, multiplicando-se a taxa de conversão pela quantidade de debêntures, encontra-se a quantidade do total de ações a serem convertidas. Quarto, obtém-se a proporção das ações convertidas sobre o total de ações da empresa após a conversão, considerando, assim, o efeito da diluição de capital com a emissão das novas ações. Finalmente, o valor da conversão é determinado pela multiplicação da proporção das ações convertidas pelo valor do patrimônio líquido do período de decisão. O patrimônio líquido é obtido subtraindo o valor dos demais passivos exigíveis do ativo total.

Do penúltimo período até o primeiro período da árvore binomial, o valor da dívida é trazido a valor presente pela fórmula de valor presente apresentada em "3.2. Precificação do Título" somando o valor dos juros anuais acruados em cada um dos períodos, exceto na data 0 da árvore binomial, quando não há período de incidência de juros. A cada período da árvore binomial, aplica-se o critério de decisão especificado em "3.4. Critério de Decisão do Valor do Passivo", levando em 
conta os componentes: (i) subordinação dos passivos financeiros aos passivos prioritários, (ii) call, (iii) conversibilidade e (iv) subordinação dos títulos de dívida a todos os demais passivos exigíveis.

Uma vez calculado o valor presente de todos os títulos de dívida da empresa, utilizando a volatilidade histórica, parte-se para o cálculo da volatilidade implícita, a qual minimiza a diferença entre o preço dos títulos calculado pelo modelo e seus respectivos valores de mercado.

A diferença entre o valor de mercado da empresa e seu patrimônio líquido, calculado pelo modelo, também é utilizado na determinação da volatilidade implícita. O patrimônio líquido é obtido subtraindo do valor total inicial dos ativos: (i) o valor presente dos títulos (calculado pelo modelo) que possuem valor de mercado e (ii) o valor contábil dos títulos que não possuem valor de mercado.

Foram coletados os valores de mercado de 30 de setembro de 2003 (com tolerância de 30 dias) de 37 dos 56 títulos avaliados. No caso dos Eurobônus, o valor de mercado, expresso como uma porcentagem da curva do papel, é multiplicado pelo valor nominal encontrando, então, o valor de mercado utilizado na comparação com o valor do modelo. No caso das debêntures, seu valor de mercado é expresso pelo preço unitário, sendo ajustado para excluir os juros acruados até a data de negociação.

Uma vez precificados todos os títulos de dívida da empresa, calcula-se a taxa de retorno das dívidas fiT-Test

Paired Samples Statistics nanceiras - Txdivsubord, conforme descrito na seção "4. Estimativa do Custo de Subordinação dos Passivos Financeiros aos Passivos Prioritários". Repete-se o cálculo de precificação dos títulos de dívida da empresa, considerando, agora, que todos os passivos financeiros - empréstimos bancários, debêntures e eurobônus - tenham a mesma ordem de prioridade das demais dívidas, exceto se o título for subordinado (título com prioridade de pagamento somente antes dos acionistas da empresa). Nesse caso, o valor presente desse título permanece inalterado.

Com os novos preços dos títulos de dívida que compõem os passivos financeiros, calcula-se a nova taxa de retorno da dívida financeira - Txdiv. Então, finalmente, calcula-se o prêmio de subordinação, conforme exposto na seção "4. Estimativa do Custo de Subordinação dos Passivos Financeiros aos Passivos Prioritários."

\section{Resultados Obtidos}

Os testes de validação do modelo supõem normalidade e foram realizados utilizando o aplicativo SPSS 10.0. O primeiro teste realizado foi o teste de comparação de médias da amostra de valor presente de 37 títulos e de seus valores de mercado ("PairedSamples T-Tesf') para verificar se a diferença entre as duas séries é diferente de 0 . O resultado obtido, apresentado abaixo, não rejeita a hipótese de que a diferença é igual a zero.

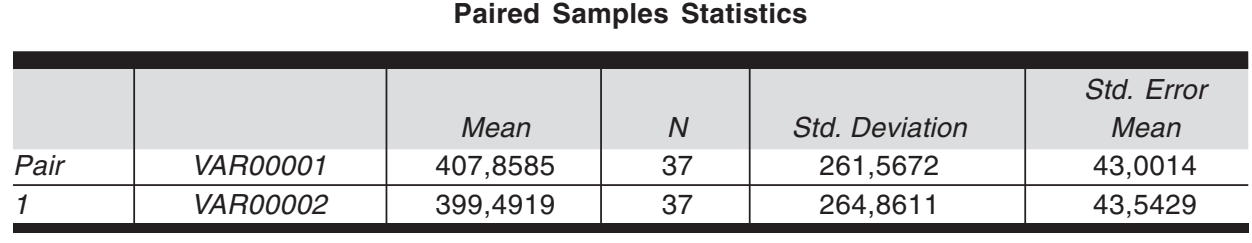

Paired Samples Correlations



Paired Samples Test

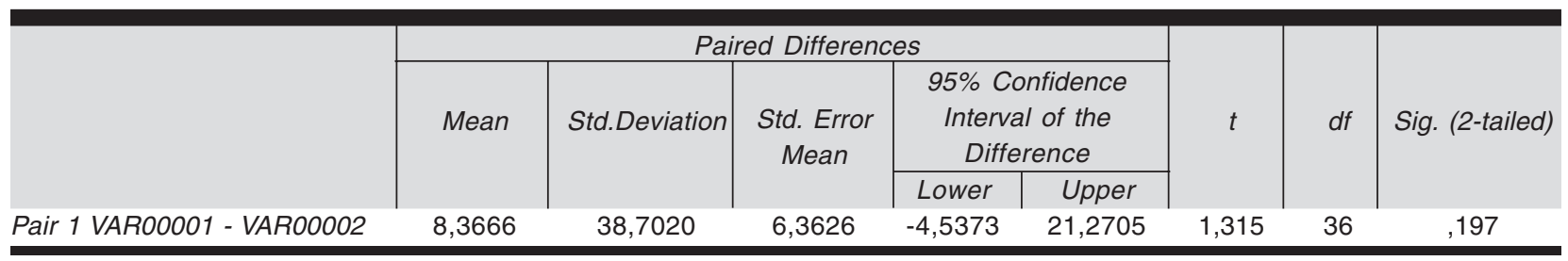

Quadro 2: Teste de Comparação de Médias - Relatório SPSS 
A característica de subordinação dos passivos financeiros aos passivos prioritários foi avaliada pelo prêmio obtido pela diferença entre as taxas de retorno obtidas pelo modelo. O valor médio dos prêmios é de $0,30 \%$ aaㅡ. Adicionalmente, determinou-se o valor médio da subordinação pela diferença do valor presente do passivo financeiro considerando-o subordinado e não subordinado. Na média, o valor da subordinação aos passivos trabalhistas equivale a 1,20\% do valor nominal dos passivos financeiros.

\begin{tabular}{|c|c|c|c|c|c|c|c|c|}
\hline \multicolumn{9}{|c|}{ Resultados lei falências } \\
\hline & \multicolumn{2}{|c|}{ Taxa de Retorno (a.a) } & \multirow[b]{2}{*}{ Prêmio } & \multirow[b]{2}{*}{$\begin{array}{c}\text { Valor } \\
\text { Nominal dos } \\
\text { Passivos } \\
\text { Financeiros }\end{array}$} & \multirow[b]{2}{*}{$\begin{array}{c}\text { Valor } \\
\text { Contábil do } \\
\text { Passivo } \\
\text { Exigível }\end{array}$} & \multicolumn{2}{|c|}{ Valor Presente-Modelo } & \multirow[b]{2}{*}{$\begin{array}{c}\text { Subordinação/ } \\
\text { Valor } \\
\text { Nominal }\end{array}$} \\
\hline & $\begin{array}{c}\text { Mesma } \\
\text { Prioridade }\end{array}$ & Subordinação & & & & $\begin{array}{c}\text { Mesma } \\
\text { Prioridade }\end{array}$ & Subordinação & \\
\hline Pão de Açucar & $8.23 \%$ & $8.77 \%$ & $0.50 \%$ & 626,117 & $2,725,382$ & 687,657 & 675,783 & $1.90 \%$ \\
\hline Brazil Telecom & $11.33 \%$ & $12.29 \%$ & $0.86 \%$ & $4,713,023$ & $8,138,371$ & $4,455,010$ & $4,382,598$ & $0.89 \%$ \\
\hline Braskem & $11.47 \%$ & $11.65 \%$ & $0.16 \%$ & $6,272,770$ & $11,582,389$ & $5,880,185$ & $5,853,973$ & $0.42 \%$ \\
\hline Cemig & $9.26 \%$ & $10.25 \%$ & $0.90 \%$ & $3,331,826$ & $8,022,745$ & $3,218,245$ & $3,048,559$ & $5.09 \%$ \\
\hline Acesita & $8.83 \%$ & $9.04 \%$ & $0.19 \%$ & $1,689,536$ & $2,532,275$ & $1,646,541$ & $1,637,844$ & $0.51 \%$ \\
\hline Petrobrás & $9.26 \%$ & $9.95 \%$ & $0.63 \%$ & $10,250,120$ & $69,802,703$ & $9,551,785$ & $9,163,619$ & $3.79 \%$ \\
\hline$\overline{\mathrm{CSN}}$ & $8.90 \%$ & $8.95 \%$ & $0.04 \%$ & $9,509,226$ & $15,559,282$ & $9,114,303$ & $9,087,003$ & $0.29 \%$ \\
\hline Usiminas & $7.52 \%$ & $7.52 \%$ & $0.00 \%$ & $2,627,940$ & $4,979,109$ & $2,642,673$ & $2,642,673$ & $0.00 \%$ \\
\hline Duratex & $10.61 \%$ & $10.61 \%$ & $0.00 \%$ & 358,937 & 613,986 & 331,220 & 331,220 & $0.00 \%$ \\
\hline Cesp & $11.74 \%$ & $12.40 \%$ & $0.59 \%$ & $9,741,111$ & $12,718,106$ & $8,363,628$ & $8,081,416$ & $2.90 \%$ \\
\hline \multicolumn{9}{|l|}{ Telesp Celular } \\
\hline Participacoes & $14.50 \%$ & $14.50 \%$ & $0.00 \%$ & $3,688,858$ & $3,903,371$ & $2,839,809$ & $2,839,693$ & $0.00 \%$ \\
\hline CPFL Energia S.A. & $10.70 \%$ & $10.70 \%$ & $0.00 \%$ & 900,000 & $1,819,210$ & 994,648 & 994,640 & $0.00 \%$ \\
\hline Sabesp & $11.27 \%$ & $11.56 \%$ & $0.26 \%$ & $7,322,642$ & $8,922,531$ & $6,663,395$ & $6,591,389$ & $0.98 \%$ \\
\hline Paranapanema & $6.44 \%$ & $6.44 \%$ & $0.00 \%$ & 601,862 & 859,558 & 595,971 & 595,971 & $0.00 \%$ \\
\hline
\end{tabular}

\section{Quadro 3: Avaliação da Subordinação aos Passivos Prioritários}

Realizou-se o teste T para verificação de que o prêmio é maior que zero. O resultado apresen- ta evidência que rejeita a hipótese de que o prêmio é igual a zero.

\section{One-Sample Statistics}

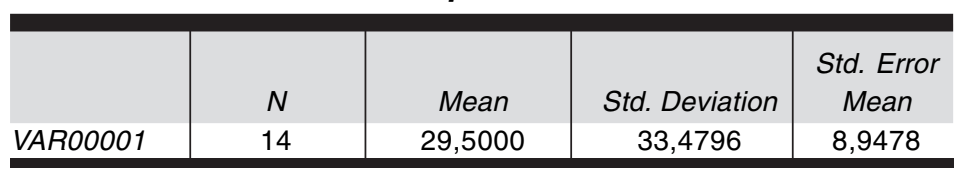

\section{One-Sample Test}

\begin{tabular}{|c|c|c|c|c|c|c|}
\hline \multicolumn{7}{|c|}{ Test Value $=0$} \\
\hline & \multirow[b]{2}{*}{$t$} & \multirow[b]{2}{*}{$d f$} & \multirow[b]{2}{*}{ Sig. (2-tailed) } & \multirow{2}{*}{$\begin{array}{c}\text { Mean } \\
\text { Difference }\end{array}$} & \multicolumn{2}{|c|}{$\begin{array}{c}95 \% \text { Confidence } \\
\text { Interval of the } \\
\text { Difference }\end{array}$} \\
\hline & & & & & Lower & Upper \\
\hline VAR00001 & 3,297 & 13 & ,006 & 29,5000 & 10,1694 & 48,8306 \\
\hline
\end{tabular}




\section{Considerações Finais}

Pode-se considerar como de interesse os resultados observados. São duas as evidências que suportam a hipótese há um prêmio positivo devido à subordinação dos passivos financeiros aos passivos prioritários, estabelecida pela atual Lei de Falências. A primeira evidência refere-se ao primeiro teste que verifica a igualdade de médias do valor presente obtido pelo modelo de precificação e o valor de mercado do título a partir da amostra de 37 títulos. A segunda evidência refere-se ao resultado do teste que rejeita a hipótese de que o prêmio de subordinação é igual a zero. A média do prêmio de subordinação é de 0,30\%a.a., indicando que as empresas pagam, em média, um prêmio de $0,30 \%$ a.a. na contratação de empréstimos e financiamentos, devido à subordinação desses passivos aos passivos trabalhistas, previdenciários e trabalhistas, estabelecida pela atual Lei de Falências.

Estas evidências sinalizam a importância da dis- cussão da ordem de prioridade das dívidas corporativas em função do prêmio na contratação de empréstimos e financiamentos, o que impacta o custo de capital das empresas. Uma redução no custo de capital poderá determinar decisões corporativas de investimento através da implementação de projetos de investimentos que passam a ser rentáveis em face de um menor custo de capital.

Finalmente, deve-se considerar as limitações deste trabalho que consistem, primeiramente, no pequeno tamanho da amostra disponível, o que dificulta de expansão das evidências empíricas aqui obtidas para o universo das demais empresas. Segundo, as estimativas dos parâmetros utilizados na aplicação desta pesquisa, como as estimativas anuais dos indicadores e a de que o custo de passivos, equivalem à taxa livre de risco (exceto as debêntures e eurobônus) e foram realizadas devido à impossibilidade de observação dos respectivos dados. Caso se dispusesse dos dados reais, poder-se-ia chegar a resultados diferentes daqueles aqui obtidos.

BIBLIOGRAFIAS

BARTH, M; LANDSMAN, W; RENDLEMAN, R. Option PricingBased Bond Value Estimates and a Fundamental Components Approach to Account for Corporate Debt. The Accounting Review. Vol.73, n 1, Jan. 1998.

. Implementation of an OptionPricing-Based Bond Valuation Model for Corporate Debt and Its Components. Accounting Horizons. Vol.14, n 4 , Dec. 2000.

BLACK, F.; SCHOLES, M. The Pricing of Options and Corporate Liabilities. Journal of Political Economy. 81, n 3 , May/Jun. 1973.

BRENNAN, M.; SCHWARTZE. Analysing Convertible Bonds. Journal of Financial and Quantitative Analysis. Vol. 15, n 4, Nov. 1980.

BODIE, Z; KANE, A; MARCUS, A. Investments. Fourth Ed., Irwin McGraw-Hill, 1999.

COPELAND T.; WESTON J. Financial Theory and Corporate Policy. Third Edition, Addison-Wesley Publishing Company, 1988.

COX, J.; ROSS, S; RUBINSTEIN, M. Option Pricing: A simplified approach. Journal of Financial Economics. Vol. 7, 1979.

COX, J.; RUBINSTEIN, M. Options Markets. Prentice-Hall, Inc., Englewood Cliffs, New Jersey, 1985.

ELTON, E.; GRUBER, M.; BROWN, S.; GOESTZMANN W. Modern Portfolio Theory and Investment Analysis. Sixth Ed. Wiley, 2002.
FABOZZI, F. A simplified model for valuing debt options. Journal of Portfolio Management. Vol. 15, n 3; Spring 1989.

KALOTAY, A; WILLIAMS, G. A Model for Valuing Bonds and Embedded Options. Financial Analysts Journal. Vol. 49, n 3 , May-Jun 1993.

Bond Markets, Analysis and Strategies. Fourth Ed., Prentice Hall, Upper Saddle River, New Jersey, 2000.

FINNERTY, J. Adjusting the Binomial Model for Default Risk. Journal of Portfolio Management. Vol. 25, n 2; Winter 1999.

FRANCIS, J. Investments Analysis and Management. Fifth Ed., McGrw-Hill, Inc., New York, 1991.

GONÇALVES, F.; BARROS, M. Pricing the Option-Adjusted Spread of Brazilian Eurobonds. The Journal of Portfolio Management. Vol. 24 № 3, Spring 1998.

HULL, J. Options, Futures and Other Derivatives. Fourth Ed., Upper Saddle River, NJ: Prentice Hall, 2000

JARROW, R.A.; TURNBULL S. Pricing Derivatives on financial securities subject to credit risk. The Journal of Finance. Vol. 50, №1, Mar 1995.

KING, D. An Empirical Examination of Call Option Values Implicit in U.S. Corporate Bonds. Journal of Financial and Quantitative Analysis. Vol 37, № 4, Dec 2002. 
LONGSTAFF, F.; SCHWARTS. A simple approach to valuing risky fixed and floating rate debt. The Journal of Finance. Vol. 50, № 3, Jul 1995.

MCCONNELL,J.; SCHWARTZ E. LYON Taming. The Journal of Finance. Vol 46, № 3, Jul 1996.

MINARDI, A.; SANVICENTE. A Estimação do Custo Médio de Capital de Empresas sob Processo de Regulação Econômica no Brasil. III Encontro Brasileiro de Finanças, São Paulo, SP, Jul. 2003.
NEWBOLD, P. Statistics for Business \& Economics. Fourth Ed., Prentice Hall, New Jersey, 1995.

RENDLEMAN, R.; BARTTER, B. Two-State Option Pricing. The Journal of Finance. Vol. 34, № 5, Dec 1979.

NOTA:

Endereço dos autores:

Universidade de São Paulo

Rua Prof. Luciano Gualberto, 908 - FEA 1

Cidade Universitária - São Paulo - SP

05508-900 